\title{
Changes in the wood boring community in the Tagus Estuary: a case study
}

\author{
L.M.S. BORGES ${ }^{1,2}$, A.A. VALENTE ${ }^{3}$, P. PALMA ${ }^{3}$ AND L. NUNES ${ }^{3}$ \\ ${ }^{1}$ Institute of Marine Sciences, School of Biological Sciences, University of Portsmouth, Ferry Road, Portsmouth PO4 9LY, UK, \\ ${ }^{2}$ Centre of Molecular and Environmental Biology (CBMA), Department of Biology, University of Minho, Campus de Gualtar, \\ 4710-057 Braga, Portugal, ${ }^{3}$ Laboratório Nacional de Engenharia Civil, Avenida do Brasil, 101, 1700-066 Lisbon, Portugal
}

\begin{abstract}
In recent years an increased shift in the geographical range of species has been documented, which coincides with global warming. On the Portuguese coast the raising of sea-surface temperatures and salinity has also been affecting the intertidal species range. The aim of the present study was to assess changes in the wood boring community present in the Tagus Estuary by comparing data from present surveys with historical records from the 1960s and 1970s. A shift in the activity of wood boring species was observed in the Tagus Estuary. In recent surveys, the main agents of wood destruction in the Tagus were Limnoria tripunctata and Limnoria quadripunctata. In the 1960 and 1970 only L. tripunctata was reported as occurring in the Tagus estuary but it was not considered at threat to wooden structures exposed in the sea. The present predominance of limnoriids in the Tagus might be related to several factors but possibly the most important was the increase in salinity in the area, as limnoriids appear to be restricted to waters with salinities closed to that of seawater. The teredinid species also changed in the area. In the 1960 s and 1970 s Teredo navalis was reported as the only teredinid species occurring in the Tagus. In recent surveys however, this species was not found, instead two other teredinid species were present Lyrodus pedicellatus and Nototeredo norvagica. The absence of $\mathrm{T}$. navalis in recent surveys might be related to competition with $\mathrm{L}$. pedicellatus.
\end{abstract}

Keywords: marine wood borers, limnoriids, teredinids, Tagus Estuary, temperature, salinity

Submitted 16 November 2009; accepted 7 March 2010

\section{INTRDロUCTION}

Climate change has been causing a shift in the geographical range of species (Parmesan \& Yohe, 2003) but the effect of seasurface warming is still poorly understood in marine systems (Rivadeneira \& Fernández, 2005). Nonetheless, some studies have been undertaken on the Portuguese coast to understand the effect of climate change in marine organisms such as rocky shore communities (Boaventura et al., 2002) and macroalgae assemblages (Lima et al., 2007). Intertidal communities are particularly attractive systems to use as models to study changes at community level as they have a shorter life-span associated with their sessile adult stages (Southward et al., 2004) and live near their thermal (Helmuth et al., 2002) and haline (Borges, 2007) tolerance limits.

An example of such a community is the intertidal wood boring community. This is a heterogeneous group that includes Crustacea of the orders Isopoda and Amphipoda and Bivalvia of the families Teredinidae and Pholadidae, which makes it possible to observe the effects of the same environmental conditions in very different organisms. Wood borers bore into wood not only for shelter but often also for nourishment. The bivalves live confined to their wood galleries and the crustaceans are poor swimmers, so marine

Corresponding author:

L.M.S. Borges

Email: Luisaborges20oo@yahoo.co.uk borers are generally unable to avoid extremes of temperature and salinity during low tide (Borges, 2007).

In Portugal maritime structures made of wood are rare and that is probably one of the reasons why wood borers have not been monitored on the Portuguese coast for the last 40 years. However, in the 1960s and early 1970s, researchers of the Laboratório Nacional de Engenharia Civil (LNEC) in Lisbon carried out long-term trials (15 year period) in the Tagus Estuary, to test several wood species for their resistance to wood boring organisms (e.g. Franco \& Farinha, 1968; Franco, 1975). The research aimed mainly at testing more durable wood species in order to find resistant wooden materials, which could be used in maritime construction. In addition, researchers from LNEC were also partners in a cooperative research programme among several European countries of the Organization for Economic Cooperation and Development (OECD), involving experts in wood preservation from 9 countries (Jones et al., 1972). The aim of this last programme was the identification and geographical distribution of wood boring and fouling organisms (Franco \& Farinha, 1968). During these trials, important information was gathered concerning wood boring species occurring in the Tagus Estuary. At the time, the only teredinid species reported as occurring in the Tagus was Teredo navalis L. Limnoriids were also found in the Tagus but in very low numbers (Neves, 1962; Franco, 1968, 1975; Franco \& Farinha, 1968).

Recently, researchers at LNEC had access to wooden pillars which supported a platform structure and had been exposed for sixteen years in the Tagus Estuary. The pillars became unserviceable because of the great level of deterioration 